International Psychogeriatrics, Vol. 5, No. 2, 1993

(C) 1993 Springer Publishing Company

\title{
Editorial
}

\section{Expanding the Opportunities for Collaborative Research}

Although scientific research is generally and appropriately initiated by individuals, there are limitations and inefficiencies inherent in studies done by individuals alone. Collaboration is the concept of our time. As an example, both the medical community and lay public recognize the urgent need for an effective antidementia drug. Sound clinical trials will require subjects sufficiently numerous for investigation, and a multicentered collaborative study approach, extending even to international collaborative clinical trials.

Collaborative studies raise several issues. Among the sites, it is imperative that the object of the study is identical, that the same methodology is used, and that there is agreement on how to report the study results. Further, there needs to be sound leadership. It is often necessary for participant leaders to share good interpersonal relationships which are cooperative, though at times competitive. Finally, sufficient financial support is needed, and it must be distributed adequately and fairly among the participants.

Further examples of such research include the following studies reported in International Psychogeriatrics: A Cross-National Self-Report Measure of Depressive Symptomatology by Margaret Gatz, Boo Johansson, Nancy Pedersen, Stig Berg, and Chandra Reynolds, addressing potential for cross-national use of the Center for Epidemiological Studies - Depression scale (CES-D) to assess selfreported symptoms of depression in adults and older adults and reported in this issue; Alzheimer's Disease is Rare in Cree by Hugh C. Hendrie, Kathleen S. Hall, Neelan Pillay, Donald Rodgers, Carol Prince, James Norton, Harry Brittain, Avindra Nath, Arthur Blue, Joe Kaufert, Paul Shelton, Brian Postl, and Benjamin Osuntokun, addressing assessment of rare prevalence of Alzheimer's disease in Cree of Northern Manitoba in contrast to higher prevalence among Englishspeaking residents of Winnipeg, Canada as reported in the Volume 5, Number 1 issue; and Dementia and Cognitive Impairment in the Oldest Old: A Comparison of Two Rating Methods by Boo Johansson and Steven H. Zarit, addressing the use and comparison of multiple methods (GDS and CR in this study) for identifying cognitive impairment and dementia, reported in Volume 3, Number 1. 
Scientific participants in a collaborative study comprise a heterogeneous group. There is a richness and diversity in their thinking, and planners must allow for varying views to develop maximally flexible strategies. The International Psychogeriatric Association is well suited to meet these criteria, and to develop an organizational system to facilitate such studies and, of course, to publish their research results.

Kazuo Hasegawa, MD, Associate Editor Gene D. Cohen, MD, PhD, Editor-in-Chief Manfred Bergener, MD, Associate Editor Sanford I. Finkel, MD, Associate Editor 